\title{
Renovation of a Drop Embryo Cultures System by Using Refined Mineral oil and the Effect of Glucose and/or Hemoglobin Added to a Serum-free Medium
}

\author{
Seungtae $\mathrm{LEE}^{1)}$, Meeyoung $\mathrm{CHO}^{1)}$, Eunjung $\mathrm{KIM}^{1)}$, Taemin $\mathrm{KIM}^{1)}$, Changkyu $\mathrm{LEE}^{1)}$, Jaeyong HAN ${ }^{1)}$ and \\ Jeongmook $\operatorname{LIM}^{1) *}$
}

${ }^{1)}$ School of Agricultural Biotechnology, Seoul National University, Suwon 441-744, Korea

(Received 30 January 2003/Accepted 21 August 2003)

ABSTRACT. This study was conducted to evaluate whether refining mineral oil and the addition of hemoglobin and/or glucose to a serumfree medium could improve in vitro-development of embryos cultured in a chemicallysemi-defined microdroplet culture system. Block strain, outbred (ICR) mouse 1- or 2-cell embryos were cultured in $5 \mu$ droplets of Chatot, Ziomek and Bavister medium overlaid with mineral oil of different types, and preimplantation development to the blastocyst stage was subsequently monitored. In the experiment 1, either Sigma (M-8410) or BDH (GPR ${ }^{\mathrm{TM}}$ ) mineral oil with or without washing was used for embryo culture and, distilled water (DW) or culture medium was used as a washing agent. As results, better $(\mathrm{P}<0.0001)$ development of 1-cell embryos was found in the Sigma than in the BDH; more blastocysts developed in Sigma oil washed with culture medium than in the others (37\% vs. $0 \%$ ). Subsequent ly, 1- (experiment 2) or 2-cell (experiment 3) embryos were cultured in the droplets overlaid with medium-washed Sigma oil, to which 0.001 $\mathrm{mg} / \mathrm{ml}$ hemoglobin and/or $5.6 \mathrm{mM}$ glucose were supplemented at the 1-cell and the 4-cell stages, respectively. Regardless of embryo stages, blastocyst formation was significantly improved by the addition of hemoglobin (54 to $48 \%$ vs. 42 to $31 \%$ in 1 -cell and 83 to $78 \%$ vs. 65 to $68 \%$ in 2-cell embryos) and this effect was independent of glucose addition. In conclusion, the selection and washing of mineral oil, and the addition of hemoglobin is beneficial for improving the efficacy of a drop embryo culture system using a serum-free medium. KEY WORDS: glucose, hemoglobin, mineral oil, mouse embryo, preimplantation development.

J. Vet. Med. Sci. 66(1): 63-66, 2004

Technical advance in gamete manipulation is fundamental for developing novel medical biotechnologies. Lots of information has been obtained from various model studies and we have developed the mouse model system of embryo culture employing serum-free media and outbred strain (Institute of Cancer Research; ICR) [10, 11]. Subsequently, a culture technique using small microdroplet of a serumfree medium has been developed. In this system, commercially-purchased mineral oil is used for preparing microdroplets, so culture medium was continuously exposes to overlaid oil throughout the culture. It is possible that the artifacts included in overaid oil directly affect on the development of embryos cultured in microdroplet by continuous exposure during in vitro-culture. This hypothesis was confirmed by recent finding showing the influence of oil on embryo development during in vitro-culture [12]. In addition, a Chatot, Ziomek and Bavister (CZB) medium [1-4] was employed as a basic medium of our culture system, but this does not contain several substrates having embryotrophic action reported in previous studies [8-11].

Consequently, a randomized, prospective study was designed to further improve our embryo culture system using the microdroplet of a serum-free medium. This study was conducted to examine 1) the effects of two types of mineral oils with or without washing and 2) the effects of glucose and/or hemoglobin added to culture medium on in vitro-development of embryos.

\footnotetext{
* Correspondence to: Lim, J., M., Embryology and Gamete Biotechnology, School of Agricultural Biotechnology, Seoul National University, Building 200, Seoul 151-742, Korea.
}

\section{MATERIAL AND METHODS}

Collection of embryos: Six-week-old ICR mice were maintained under controlled lighting conditions (14L:10D) and superovulated with the injection of 5 IU PMSG (Folligon; Intervet Co., The Netherlands). For collecting in vivofertilized embryos, 5 IU hCG (Chorulonl; Intervet Co.) was administered $48 \mathrm{hr}$ after PMSG injection, and mating was concomitantly initiated with hCG injection. Coitus was evaluated by the presence of a vaginal plug $16 \mathrm{hr}$ after hCG injection, and embryos developed to the 1- (with male and female pronuclei) or 2-cell stages were collected from the oviduct of mice mated 18 or $42 \mathrm{hr}$ after hCG injection, respectively.

Culture medium: The basic medium used for the culture of embryos was $\mathrm{CZB}$ medium, consisting of $\mathrm{NaCl}(81.6$ $\mathrm{mM}), \mathrm{KCl}(4.8 \mathrm{mM}), \mathrm{KH}_{2} \mathrm{PO}_{4}(1.2 \mathrm{mM}), \mathrm{MgSO}_{4} \bullet 7 \mathrm{H}_{2} \mathrm{O}(1.2$ $\mathrm{mM}), \mathrm{CaCl}_{2} \cdot 2 \mathrm{H}_{2} \mathrm{O}(1.7 \mathrm{mM}), \mathrm{NaHCO}_{3}(25.1 \mathrm{mM})$, sodium lactate $(31.3 \mathrm{mM})$, sodium pyruvate $(0.3 \mathrm{mM})$, glutamine $(1$ $\mathrm{mM})$, EDTA $(0.1 \mathrm{mM})$, and BSA $(5 \mathrm{mg} / \mathrm{ml})$. According to the experimental design, glucose $(5.6 \mathrm{mM})$ and/or $\mathrm{Hb}$ $(0.001 \mathrm{mg} / \mathrm{ml}$, methemoglobin type) were added to CZB medium. All medium substrates were purchased from Sigma-Aldrich Co. (St Louis, MO), and the osmolarity and $\mathrm{pH}$ of the medium after preparation were within the range of 270 to $275 \mathrm{mOsm}$ and 7.28 to 7.38 , respectively. Medium was stored at $4{ }^{\circ} \mathrm{C}$ and freshly prepared every 2 weeks.

Culture of embryos and assessment of preimplantation development: A group of 20 to 24 embryos was cultured in a $5 \mu \mathrm{l}$ droplet of $\mathrm{CZB}$ medium at $37^{\circ} \mathrm{C}, 5 \% \mathrm{CO}_{2}$ in air atmosphere. Gas equilibration of the culture medium was per- 
formed for at least $3 \mathrm{hr}$ before culture. The droplets of equilibrated medium were overlaid with mineral oils of 6 different types. Number of embryos developed to the 2-cell, 4-cell, 8-cell, morula and blastocyst stages were monitored under an inverted microscope at 42, 66, 90, 114 and $138 \mathrm{hr}$ after hCG injection, respectively.

Preparation of mineral paraffin oil: Mineral oils purchased from two venders (M-8410, Sigma-Aldrich Co. and $\mathrm{GPR}^{\mathrm{TM}}$, BDH Co.) were provided for each experiment. For washing, each was mixed with the same volume of distilled water (DW) deionized by a Milli-Q system (Milli Q, Tokyo, Japan) or culture medium. Vigorous agitation was frequently done for 3 days and, after separated from the washing agent, washed oil was stored at $37^{\circ} \mathrm{C}$ in air atmosphere until use.

Experimental design and statistical analysis: Embryos were randomly allocated in each experimental treatment and all experiments replicated 5 times. In Experiment 1, 1-cell embryos were cultured in medium droplets overlaid by 1) Sigma oil without washing, 2) Sigma oil washed with DW, 3) Sigma oil washed with medium, 4) BDH oil without washing, 5)BDH oil washed with DW or 6) BDH oil washed with medium. Medium used for washing was CZB medium, but BSA was not added. In Experiment 2 using 1-cell and Experiment 3 using 2-cell embryos, BSA-free CZB medium was supplemented with 1) no addition, 2) glucose at the 4cell stage, 3) hemoglobin from onset of culture, or 4) hemoglobin and glucose from onset of culture and at the 4-cell stage, respectively. Culture droplets were overlaid by Sigma oil washed with medium. The percentage of embryos developed to each preimplantation stage was subjected to a generalized linear model (PROC-GLM) in a Statistical Analysis System (SAS) program. When significance of the main effects was detected in each experimental parameter, treatment effects were subsequently compared by the least square method. Significant difference among treatments was then determined where the P value was less then 0.06 .

\section{RESULTS}

Experiment 1: A significant $(\mathrm{P}<0.0001)$ model effect was found in the development beyond the 2-cell stage after the treatment. As shown in Table 1,37\% of cultured embryos developed to the blastocyst stage in the medium-washed Sigma oil groups, but no blastocyst formation was detected in the others. Overall, Sigma oil yielded better $(\mathrm{P}<0.05)$ preimplantation development (11 to $66 \%$ vs. 0 to $1 \%, 11$ to $72 \%$ vs. 0 to $2 \%, 15$ to $73 \%$ vs. 0 to $17 \%$ and 85 to $88 \%$ vs. 0 to $63 \%$ in morula, 8 -cell, 4-cell and 2-cell stage, respectively) than BDH oil. When used Sigma oil, washing with medium was more favorable to embryo development than washing with DW. Embryos could not cleave during culture when $\mathrm{BDH}$ oil was used without washing, while embryos cultured in droplets overlaid with Sigma oil without washing developed up to the morula stage.

Experiment 2: As shown in Table 2, significant $(\mathrm{P}<0.0042)$ model effects were found in blastocyst formation after the treatments. $\mathrm{Hb}$ addition to $\mathrm{CZB}$ medium significantly $(\mathrm{P}=0.0072)$ promoted blastocyst formation (48\% vs. $31 \%$ ) in the absence of glucose and such an effect was not affected by the addition of glucose at the 4-cell stage ( $42 \%$ vs. $54 \% ; \mathrm{P}=0.083$ ). The highest blastocyst formation was achieved by combined addition of $\mathrm{Hb}$ and glucose, but glucose alone did not improve preimplantation development. There were no significant differences in the development to the 2-cell (91 to 97\%), 4-cell (76 to 82\%), 8-cell (71 to $79 \%$ ) and morula (61 to $73 \%$ ) stages among treatments.

Experiment 3: In blastocyst formation, a similar treatment effect was found compared with the results from Experiment 2 (Table 3). More $(\mathrm{P}<0.06)$ embryos developed to blastocysts after $\mathrm{Hb}$ addition than after no addition, regardless of the presence $(65 \%$ vs. $83 \%)$ and absence $(68 \%$ vs. $78 \%$ ) of glucose from the 4-cell stage. No significant treatment effect was found in the development to the 4-cell $(98$ to $99 \%$ ), 8-cell (94 to $97 \%$ ) and morula (92 to $96 \%$ ) stages.

Table 1. Effects of type and washing of mineral paraffin oils used for a drop culture on preimplantation development of ICR mouse embryos cultured in a Chatot, Ziomek and Bavister (CZB) medium supplemented with BSA (5 mg/ $\mathrm{m} l)$

\begin{tabular}{|c|c|c|c|c|c|c|c|}
\hline \multirow[b]{2}{*}{$\begin{array}{l}\text { Oil } \\
\text { venders }\end{array}$} & \multirow[b]{2}{*}{ Washing agents } & \multirow{2}{*}{$\begin{array}{l}\text { No. of } \\
\text { embryos } \\
\text { cultured }^{\mathrm{c}}\end{array}$} & \multicolumn{5}{|c|}{ No. $(\%)$ of embryos developed to } \\
\hline & & & $\begin{array}{l}\text { 2-cell } \\
{[42]^{\text {d) }}}\end{array}$ & $\begin{array}{l}4 \text {-cell } \\
{[66]^{\text {d) }}}\end{array}$ & $\begin{array}{l}8 \text {-cell } \\
{[90]^{\text {d) }}}\end{array}$ & $\begin{array}{l}\text { Morula } \\
{[114]^{\text {d) }}}\end{array}$ & $\begin{array}{c}\text { Blastocyst } \\
{[138]^{\mathrm{d})}}\end{array}$ \\
\hline \multirow{3}{*}{$\mathrm{BDH}^{\mathrm{a})}$} & None & 104 & $0(0)^{\mathrm{e})}$ & $0(0)^{\mathrm{e})}$ & $\left.0(0)^{\mathrm{e}}\right)$ & $\left.0(0)^{\mathrm{e}}\right)$ & $0(0)^{\mathrm{e})}$ \\
\hline & Distilled water & 102 & $75(74)^{\mathrm{f})}$ & $17(17)^{\mathrm{f})}$ & $2(2)^{\mathrm{e})}$ & $1(1)^{\mathrm{e})}$ & $0(0)^{\mathrm{e})}$ \\
\hline & Culture medium & 114 & $\left.72(63)^{g}\right)$ & $0(0)^{\mathrm{e})}$ & $0(0)^{\mathrm{e}}$ & $0(0)^{e}$ & $0(0)^{\mathrm{e})}$ \\
\hline \multirow[t]{3}{*}{ Sigma $^{\text {b) }}$} & None & 101 & $88(87)^{\mathrm{h})}$ & $15(15)^{\mathrm{f})}$ & $11(11)^{\mathrm{f})}$ & $11(11)^{\mathrm{f})}$ & $0(0)^{\mathrm{e})}$ \\
\hline & Distilled water & 104 & $88(85)^{\mathrm{h})}$ & $64(62)^{\mathrm{g})}$ & $40(38)^{\mathrm{g})}$ & $\left.34(33)^{g}\right)$ & $0(0)^{\mathrm{e})}$ \\
\hline & Culture medium & 101 & $86(85)^{\mathrm{h})}$ & $74(73)^{\mathrm{h})}$ & $73(72)^{\mathrm{h})}$ & $67(66)^{\mathrm{h})}$ & $37(37)^{\mathrm{f}}$ \\
\hline
\end{tabular}

Model effect of treatments in each parameter, which is indicated as the $\mathrm{P}$ value, was less than 0.0001 in all experimental parameters.

a) Cat no. Prod $294365 \mathrm{H}$ purchased from BDH Co.

b) Cat no. M-8410 purchased from Sigma-Aldrich Co.

c) One-cell embryos were retrieved by oviduct flushing $16 \mathrm{hr}$ post-hCG injection.

d) Numbers in parenthesis indicate hours post-hCG injection.

e), f), g), h) Different subscripts within a column are significantly different, $\mathrm{P}<0.05$. 
Table 2. Combined effects of the addition of hemoglobin $(0.001 \mathrm{mg} / \mathrm{m} l)^{\mathrm{a})}$ and/or glucose $\left.(5.6 \mathrm{mM})^{\mathrm{b}}\right)$ to BSA $(5 \mathrm{mg} / \mathrm{ml}$ )-supplemented Chatot, Ziomek and Bavister (CZB) medium on preimplantation development of ICR mouse 1-cell embryos cultured in droplets of the medium covered with mediumwashed Sigma-Aldrich mineral paraffin oil

\begin{tabular}{|c|c|c|c|c|c|c|c|}
\hline \multicolumn{2}{|c|}{$\begin{array}{l}\text { Medium with (+) or } \\
\text { without (-) }\end{array}$} & \multirow{2}{*}{$\begin{array}{c}\text { No. of } \\
\text { embryos }^{\mathrm{c})} \\
\text { cultured }\end{array}$} & \multicolumn{5}{|c|}{ No. (\%) of embryos developed to } \\
\hline Hemoglobin & Glucose & & $\begin{array}{l}2 \text {-cell } \\
{[42]^{\text {d) }}}\end{array}$ & $\begin{array}{l}\text { 4-cell } \\
{[66]^{\mathrm{d})}}\end{array}$ & $\begin{array}{l}8 \text {-cell } \\
{[90]^{\mathrm{d})}}\end{array}$ & $\begin{array}{l}\text { Morula } \\
{[114]^{\mathrm{d})}}\end{array}$ & $\begin{array}{l}\text { Blastocyst } \\
{[138]^{\mathrm{d})}}\end{array}$ \\
\hline+ & + & 99 & $90(91)$ & $75(76)$ & $73(74)$ & $72(73)$ & $54(54)^{\mathrm{e})}$ \\
\hline+ & - & 97 & 94 (97) & $79(81)$ & $73(75)$ & $64(66)$ & $48(48)^{\mathrm{e})}$ \\
\hline - & + & 99 & $94(95)$ & $81(82)$ & $78(79)$ & $69(70)$ & $42(42)^{\mathrm{f})}$ \\
\hline - & - & 104 & $96(92)$ & $79(76)$ & $74(71)$ & $63(61)$ & $\left.32(31)^{\mathrm{f}}\right)$ \\
\hline
\end{tabular}

Model effect of treatments in each parameter, which is indicated as the $P$ value, was $0.3078,0.5779,0.6548$ 0.2874 and 0.0042 , in the development to the 2-cell, 4-cell, 8-cell, morula and blastocyst stages, respectively.

a) Added to CZB medium from onset of culture.

b) Added to CZB medium from $66 \mathrm{hr}$ post-hCG injection

c) One-cell embryos were retrieved by oviduct flushing $16 \mathrm{hr}$ post-hCG injection.

d) Numbers in parenthesis indicate hours post-hCG injection.

e), f) Different subscripts within a column are significantly different, $\mathrm{P}<0.06$

Table 3. Combined effects of the addition of hemoglobin $(0.001 \mathrm{mg} / \mathrm{m} l)^{\mathrm{a})}$ and/or glucose $(5.6$ $\mathrm{mM})^{\text {b) }}$ to BSA $(5 \mathrm{mg} / \mathrm{m} l)$-supplemented Chatot, Ziomek and Bavister (CZB) medium on preimplantation development of ICR mouse 2-cell embryos cultured in droplets of the medium covered with medium-washed Sigma-Aldrich mineral paraffin oil

\begin{tabular}{|c|c|c|c|c|c|c|}
\hline \multicolumn{2}{|c|}{$\begin{array}{c}\text { Medium with (+) or } \\
\text { without (-) }\end{array}$} & \multirow{2}{*}{$\begin{array}{c}\text { No. of } \\
\text { embryos }^{\mathrm{c})} \\
\text { Cultured }\end{array}$} & \multicolumn{4}{|c|}{ No. $(\%)$ of embryos developed to } \\
\hline Hemoglobin & Glucose & & $\begin{array}{l}\text { 4-cell } \\
{[66]^{\mathrm{d})}}\end{array}$ & $\begin{array}{l}8 \text {-cell } \\
{[90]^{\text {d) }}}\end{array}$ & $\begin{array}{l}\text { Morula } \\
{[114]^{\text {d) }}}\end{array}$ & $\begin{array}{c}\text { Blastocyst } \\
{[138]^{\mathrm{d})}}\end{array}$ \\
\hline+ & + & 113 & $111(98)$ & $109(96)$ & $108(96)$ & $94(83)^{\mathrm{e})}$ \\
\hline+ & - & 114 & $113(99)$ & 111 (97) & $110(96)$ & $89(78)^{\mathrm{e})}$ \\
\hline - & + & 112 & 111 (99) & 109 (97) & $106(95)$ & $73(65)^{f)}$ \\
\hline - & - & 112 & $110(98)$ & $105(94)$ & $103(92)$ & $76(68)^{\mathrm{f})}$ \\
\hline
\end{tabular}

Model effect of treatments in each parameter, which is indicated as the $\mathrm{P}$ value, was $0.8779,0.4440$, 0.4665 and 0.0056 , in the development to the 2-cell, 4-cell, 8-cell, morula and blastocyst stages, respectively.

a) Added to CZB medium from onset of culture.

b) Added to CZB medium from $66 \mathrm{hr}$ post-hCG injection.

c) Two-cell embryos were retrieved by oviduct flushing $42 \mathrm{hr}$ post-hCG injection.

d) Numbers in parenthesis indicate hours post-hCG injection.

e), f) Different subscripts within a column are significantly different, $\mathrm{P}<0.05$

\section{DISCUSSION}

Our results demonstrated that refining and selection of mineral oil used for a serum-free, drop culture system critically affect in vitro-development of ICR mouse embryos and that more blastocysts were obtained after the addition of $\mathrm{Hb}$ to a serum-free medium. Fifty-four and $83 \%$ 1- and 2cell embryos developed to blastocysts after cultured in droplets of Hb-containing medium overlaid with Sigma oil washed with CZB medium.

Results showing the beneficial effect of Sigma oil washed with medium suggest the possibility that mineral oils tested in this study contain certain substances inhibiting mouse embryo development. Sigma oil used in our study is embryo culture tested, while BDH not, so it is highly possi- ble that BDH oil have more embryotoxic substances than Sigma oil. Our results further showed that embryotoxic artifacts presumptively included in tested oils have hydrophilic nature and easily diffuse to embryo culture medium. However, it is difficult to trace the origin of embryotoxic factors mixed with oil due to unknowable manufacturing process. Furthermore, it is not clear whether such embryotoxic substances have the same effects on embryo development in other species. Although both oils were generally used for culturing porcine and bovine embryos even without washing in our laboratory, no prospective comparison between with and without washing has not been made yet. At least, the artifacts in the oils do not severely inhibit the development of bovine or porcine embryos since, despite of using no-washed oil, the rates of preimplantation development in 
both species in our laboratory were not inferior to those in others.

From different viewpoints, difference in the chemical nature of oils might also affect embryo development. $\mathrm{BDH}$ oil had higher density $(0.86 \mathrm{~g} / \mathrm{m} l$ vs. $0.84 \mathrm{~g} / \mathrm{m} l)$ and viscosity (30 Cps vs. $26 \mathrm{Cps}$ ) than Sigma oil. These differences might influence the protective and neutralizing action of oils, which affects the infusion of toxic artifacts into embryo culture environment. A drop culture system tested in this study was more susceptible for such chemical nature, since it employed extremely small volume $(5 \mu l)$ of microdropts than others $(50-100 \mu l)$. On the other hand, batch of oil might affect experimental results of this study. At least in the use of Sigma oil, favorable results continuously obtained by washing with medium, regardless of using different batches to date (unpublished data, not shown).

Another inquiry could ascertain why medium washing is more effective than DW washing. Probably some of substrates in washing medium have a beneficial action in removing embryotoxic substances from the oils. On the other hand, results showing the superiority of Sigma oil to $\mathrm{BDH}$ oil, regardless of washing type suggested that embryotoxic artifacts in the Sigma are different from those in the $\mathrm{BDH}$.

It was informed that NO induces apoptosis resulted developmental arrest and that such detrimental action of NO on embryo development could be blocked by the treatment with $\mathrm{Hb}$, a $\mathrm{NO}$ scavenger. A promoting action of $\mathrm{Hb}$ was found in the mouse $[10,11]$, as well as in cattle $[8,9]$. The results of this study further suggest that an embryotropic action of $\mathrm{Hb}$ on ICR mouse embryo is also found in a drop embryo culture system employing CZB medium. Promoting effect of $\mathrm{Hb}$ might be independent of general substances consisting of several media, since $\mathrm{Hb}$ effect was prominent even after added to culture media with different composition.

In contrast to the promoting action of $\mathrm{Hb}$, the treatment of embryos with exogenous glucose could not further stimulate embryo development to the blastocyst stage in this study (Tables 2 and 3). It has been generally accepted from previous studies [5-9] that late preimplantation development is stimulated by exposure of developing embryos to glucose. This inconsistency might be due to the source of embryos and the time of embryo collection in vivo. Our preliminary data (date not shown) demonstrated the response of embryos to exogenous glucose is different according to the time of embryo collection. Collection at $18 \mathrm{hr}$ after hCG injection was less sensitive than collection at 14 to $16 \mathrm{hr}$ after hCG injection. Apparently, further studies will be necessary to elucidate the precise relationship between the time of embryo collection and the glucose effect.

In conclusion, although further study is necessary to pro- vide much additional information on artifacts in commercially-available oils, the results of this study showing the importance of oil washing contribute to establishing an effective embryo culture system for various purposes.

ACKNOWLEDGMENT. The authors acknowledge a graduate fellowship provided by the Korean Ministry of Education through the Brain Korea 21 project. This work was supported by Health Industry Development program from Korean Ministry of Health and Welfare.

\section{REFERENCES}

1. Chatot, C. L., Ziomek, C. A., Bavister, B. D., Lewis, J. L. and Torres, I. 1989. An improved culture medium supports development of random-bred 1-cell mouse embryos in vitro. $J$. Reprod. Fertil. 86: 679-688.

2. Chatot, C. L., Lewis, J. L., Torres, I. and Ziomek, C. A. 1990. Development of 1-cell embryos from different strains of mice CZB medium. Biol. Reprod. 42: 432-440.

3. Chatot, C. L., Tasca, R. J. and Ziomek, C. A. 1990. Glutamine uptake and utilization by preimplantation mouse embryos in CZB medium. J. Reprod. Fertil. 89: 335-346.

4. Chatot, C. L., Lewis-Williams, J., Torres, I. and Ziomek, C. A 1994. One-minute exposure of 4-cell mouse embryos to glucose overcomes morula block in CZB medium. Mol. Reprod. Dev. 37: 407-412.

5. Ellington, S. K. L. 1989. In vitro analysis of glucose metabolism and embryonic growth in postimplantation rat embryos. Development 100: 431-439.

6. Franchesca, D. H., Jeremy, G. T., Christopher, J. K. and Henry, J. L. 1996. Oxygen consumption and energy metabolism of the early mouse embryo. Mol. Reprod. Dev. 44: 476-485.

7. Gardner, D. K. and Leese, H. J. 1988. The role of glucose and pyruvate transport in regulating nutrient utilization by preimplantation mouse embryos. Development 104: 423-429.

8. Lim, J. M. and Hansel, W. 1998. Improved development of in vitro-derived bovine embryos by use of a nitric oxide scavenger in a cumulus-granulosa cell coculture system. Mol. Reprod. Dev. 50: 45-43.

9. Lim, J. M., Mei, Y., Chen, B., Godke, R. A. and Hansel, W. 1999. Development of bovine IVF oocytes cultured in medium supplemented with a nitric oxide scavenger or inhibitor in a coculture system. Theriogenology 51: 941-949.

10. Park, S. E., Chung, H. M., Cha, K. Y., Hwang, W. S., Lee, E. S. and Lim, J. M. 2001. Establishment of an animal embryo culture system containing various embryotropins and its efficacy for culturing ICR mouse one-cell embryos derived in vivo or in vitro. Fertil. Steril. 76: 167-174.

11. Park, S. E., Chung, H. M., Ko, J. J., Lee, B. C., Cha, K. Y. and Lim, J. M. 2000. Embryotropic role of hemoglobin and ethylenediaminetetraacetic acid in preimplantation development of ICR mouse 1-cell embryos. Fertil. Steril. 74: 996-1000.

12. Van Soom, A., Mahmoudzadeh, A. R., Christophe, A., Ysebaert, M. T. and de Kruif, A. 2001. Silicone oil used in microdrop culture can affect bovine embryonic development and freezability. Reprod. Domest. Anim. 36: 169-176. 